\title{
METODOLOGIAS ATIVAS NA FORMAÇÃO INICIAL DE PROFESSORES: O ENSINO DE CIÊNCIAS A PARTIR DA ABP
}

\author{
ACTIVE METHODOLOGIES IN THE INITIAL TEACHER TRAINING: SCIENCE \\ TEACHING FROM ABP
}

\author{
METODOLOGÍAS ACTIVAS EN LA FORMACIÓN INICIAL DEL PROFESOR: \\ ENSEÑANZA DE LAS CIENCIAS DESDE ABP
}

\author{
Maria Joicilene Santana da Silva ${ }^{1}$ \\ Silvana Neumann Martins ${ }^{2}$
}

\begin{abstract}
RESUMO: Este estudo investigou em que aspectos a metodologia ativa de Aprendizagem Baseada em Problemas (ABP), contribui para a formação inicial de professores de Biologia. Constituiu-se em uma abordagem qualitativa, que se aproxima da pesquisa-ação. As informações foram obtidas em uma oficina, ministrada aos acadêmicos, do curso de Licenciatura em Biologia da Universidade Federal do Oeste do Pará - UFOPA, em Santarém - PA, na disciplina Prática de Ensino de Biologia I, momento que vivenciaram a proposta metodológica. Os resultados analisados a partir do olhar do pedagogo/pesquisador com foco no ensino, indicou que: integrar métodos ativos na licenciatura apresenta-se como promissor, onde as reflexões sobre teorias e práticas de ensino de forma integrada e contextualizada, indicaram possíveis mudanças frente às futuras decisões pedagógicas.
\end{abstract}

Palavras- chave: Ensino. Formação Inicial de Professores. Ensino de Biologia. Aprendizagem Baseada em Problemas. Teoria-Prática-Metodologias.

ABSTRACT: This study investigated in which aspects the active methodology of Problem-Based Learning (PBL), contributes to the initial training of Biology teachers. It consisted of a qualitative approach, which is close to action research. The information was obtained in a workshop, given to academics, in the Biology Degree course at the Federal University of Western Pará - UFOPA, in Santarem - PA, in the discipline of Teaching Biology I, when they experienced the methodological proposal. The results analyzed from the point of view of the pedagogue / researcher with a focus on teaching, indicated that: integrating active methods in the undergraduate program presents itself as promising, where reflections on teaching theories and practices in an integrated and contextualized way, indicated possible changes in face of the future pedagogical decisions.

Keywords: Teaching. Initial Teacher Training. Biology teaching. Problem-Based Learning. TheoryPractice-Methodologies.

\footnotetext{
1 Pedagoga, Especialista em Docência. Mestre em Ensino de Ciências Exatas com foco em Metodologias Ativas.E-mail:maria.silva25@universo.univates.br.

2 Doutora, professora dos Programas de Pós-Graduação em Ensino e Ensino de Ciências Exatas Pesquisadora em Formação de Professores, Pedagogia Empreendedora e Metodologias Ativas/Participativas de Ensino e de Aprendizagem Universidade do Vale do Taquari - Univates.
} 
RESUMEN: Este estudio investigó en qué aspectos la metodología activa del Aprendizaje Basado en Problemas (ABP), contribuye a la formación inicial de los profesores de Biología. Consistió en un enfoque cualitativo, cercano a la investigación-acción. La información se obtuvo en un taller, impartido a académicos, en la carrera de Licenciatura en Biología de la Universidad Federal de Pará Occidental - UFOPA, en Santarém - PA, en la disciplina de Enseñanza de la Biología I, cuando experimentaron la propuesta metodológica. Los resultados analizados desde el punto de vista del pedagogo / investigador con enfoque docente, indicaron que: la integración de métodosf activos en la carrera se presenta como promisoria, donde las reflexiones sobre la enseñanza de teorías y prácticas de manera integrada y contextualizada, indicaron posibles cambios de cara a las futuras decisiones pedagógicas.

Palabras clave: Docencia. Formación inicial del profesorado. Enseñanza de la biología. Aprendizaje basado en problemas. Teoría-Práctica-Metodologías.

\section{INTRODUÇÃO}

Contextualizar o conhecimento científico produzido nos cursos de licenciatura à realidade do aluno não é uma tarefa fácil. Muitas vezes, tal aproximação representa um entrave para a prática de ensino, visto que, em algumas situações, os professores vem apresentando dificuldades em vincular os conteúdos científicos aos conhecimentos prévios dos alunos. Nas áreas de Ciências Exatas e Naturais, essa dificuldade é ainda mais saliente, visto que muitos conteúdos são abstratos e exigem do aluno maior capacidade de raciocínio abstração e imaginação (CARVALHO,2015).

Soma-se a isso o fato de, durante a formação inicial, muitas vezes, o professor não é devidamente preparado para desenvolver competências que favoreçam à contextualização do conteúdo na sala de aula. Para Carvalho (2015), as ideias inovadoras e criativas sobre o ensino de determinado conteúdo, disponibilizadas durante o curso de formação, são muito gerais e, por vezes, não são acompanhadas por uma prática compatível.

Assim, durante a prática de ensino em sala de aula é que as dificuldades podem surgir, mesmo conhecendo o conteúdo teórico, muitos docentes enfrentam obstáculos ao ensinar os conteúdos da matriz curricular da Educação Básica aos alunos. Dessa forma, ao se depararem com as avaliações a que seus alunos são submetidos, percebem que eles não atingiram o objetivo proposto e que não houve indícios de aprendizado. Com isso, espalhase entre os professores uma crescente sensação de frustrações, de receios e de incertezas (POZO; CRESPO, 2009). 
Buscando reverter situações de entraves ao ensino e à aprendizagem, como a descrita anteriormente, alguns professores recorrem à imitação, à reprodução e, às vezes, à reelaboração de modelos existentes e consagrados. Assim, tornam a sala de aula um verdadeiro laboratório de estratégias e métodos de ensino, experimentando metodologias, a fim de promover a aprendizagem. Além disso, também dialogam com seus colegas educadores mais experientes, para trocarem informações que possam melhorar tanto o seu desempenho, como o de seus alunos (PIMENTA; LIMA, 2010).

Ademais, a pesquisa deve constituir-se como objetivo do ato educativo, fazendo do aluno um parceiro de trabalho autônomo, ativo, participativo e reconstrutivo (DEMO, 2002). A partir dessa reflexão, questiona-se: será que o docente, em sua formação inicial, vem sendo preparado para integrar a pesquisa em sua prática pedagógica?

Além de contextualizar o conteúdo, aproximando-o dos conhecimentos prévios dos alunos, reafirma-se que uma abordagem de ensino voltada para a pesquisa pode ser um dos caminhos na tentativa de melhorar a aprendizagem e, portanto, contribuindo também em melhorar os resultados desfavoráveis apresentados em avaliações, pois o próprio aluno, ao realizar suas pesquisas, fará as conexões com o que já sabe. Ademais, para contextualizar o conhecimento, é preciso inserir, no âmbito do ensino formal, estratégias de ensino provocantes, dinâmicas e ativas, principalmente nas aulas de Ciências/Biologia, uma vez que ensinar e aprender essa disciplina envolve desafios que requerem estratégias adequadas para que se chegue ao objetivo da aula.

Como a Aprendizagem Baseada em Problemas é um método ativo que propõe um ensino com base em inserir a pesquisa nas aulas de forma dialogada e colaborativa, convém questionar em que realmente essa proposta contribui no processo de aprendizagem, assim surge o seguinte problema: Em que aspectos uma proposta de ensino, embasada nos pressupostos da Aprendizagem Baseada em Problemas, contribui para a formação inicial de professores de Biologia do oeste do Pará? Na tentativa de compreender se o método ativo produz aprendizagens, propomos inserir a proposta metodológica de Aprendizagem Baseada em problemas nas às aulas da formação inicial de professores, sendo assim, 
convém esclarecer que deste ponto em diante, quando nos referirmos ao método ativo, Aprendizagem Baseada em Problemas utilizaremos a sigla ABP.

Consequentemente, a partir dessa inquietação sobre saber em que contribui a $A B P$ para os processos de ensino e de aprendizagem, surgiu a ideia de promover uma vivência, por meio de uma oficina, objetivando instigar os acadêmicos a buscarem conhecer novas formas de ensinar. Acredita-se que, ao vivenciar novas experiências, os professores têm uma segurança maior para aplicaram tais práticas em suas aulas, tornando-as um ambiente de constante pesquisa e construção de conhecimentos significativos.

Assim, realizou-se uma oficina que objetivou proporcionar aos acadêmicos de Licenciatura em Ciências Biológicas da Universidade Federal do Oeste do Pará, durante a disciplina de Prática de Biologia I, um período em que vivenciaram a proposta metodológica de ABP. A oficina possibilitou, também, que os acadêmicos experienciassem um ensino que articula teoria e prática de forma contextualizada, isto é, aulas em que conteúdos de Ciências/Biologia do ensino básico eram acompanhados por um contexto intelectual e cultural intrínseco, uma das características da proposta de ABP.

Nesse sentido, integrar o ensino à vida dos participantes significa que o saber deles e sua experiência de vida são fundamentais para a construção da aprendizagem. Outra característica típica do método ativo proposto no estudo é a inserção da situaçõesproblema, que foram usadas como gatilhos para que os acadêmicos se questionarem e refletirem sobre suas "certezas".

Refletindo sobre o processo de ensino das disciplinas, a realização desta investigação fez-se necessária, promovendo vivências práticas que estimularam a mudança de percepção sobre a prática de ensino na atuação profissional do futuro professor. Mesmo sabendo que cada realidade pode revelar resultados diferentes, dependendo do público a que se destina, há situações de aprendizagem em que as metodologias de ensino podem ser adaptadas ou reelaborados para atender as necessidades de cada contexto.

Para tanto, considera-se que a proposta da Aprendizagem Baseada em Problemas (ABP) seja uma oportunidade de ofertar aos acadêmicos do Ensino Superior a possibilidade de refletirem criticamente sobre a realidade de ensino. Essa reflexão se dá, 
pois, a referida metodologia se desenvolve por meio das habilidades de analisar, dialogar, pesquisar e buscar soluções viáveis para situações-problemas cotidianas, que podem ser encontradas nos conteúdos programáticos ensinados na Educação Básica.

É importante esclarecer que no Brasil existem ainda poucos estudos dentro de como desenvolver a ABP integrada as aulas da formação inicial de professores, pelo menos foi o que ficou entendido, após fazer uma pesquisa acerca dos trabalhos que abordam o tema no Brasil, na plataforma sucupira, no ano 2019, a partir da qual evidenciou-se que a ABP se encontra presente no ano de 2019 em II 46.342 estudos, porém ao restringir-se o períodos, e utilizar palavras ou expressões como PBL (sigla em inglês para ABP) na formação de professores; Aprendizagem Baseada em Problemas no curso de Biologia, na pesquisa realizada na Plataforma Sucupira, não foram encontradas produções diretamente ligadas à $\mathrm{ABP}$ na formação inicial de professores de Ciências Biológicas. Isso evidencia o ineditismo deste estudo e, mais uma vez, ratifica sua relevância.

Assim, esse estudo buscou mostrar, em uma oficina, como os conteúdos de Ciências e Biologia que constam na matriz curricular da Educação Básica podem ser ensinados utilizando a proposta metodológica de $\mathrm{ABP}$, e que essa proposta possibilita articular esses conteúdos, de forma contextualizada, à realidade dos alunos.

E dessa maneira favorecer a compreensão dos acadêmicos acerca da proposta implementada e de como integrá-la às suas aulas. Pelo fato de terem vivenciado a metodologia, acredita-se que se sintam mais seguros para integrarem-na ao seu fazer pedagógico. Sendo a oficina, o caminho escolhido para responder nosso objetivo. Assim na seção seguinte é apresentada a segunda fase deste estudo que trata dos Pressupostos Teóricos, em que se abordam as principais concepções sobre os temas abordados durante o estudo.

\section{Pressupostos Teóricos}

\section{O Ensino por meio da ABP na formação inicial de professores}

Para alcançar o propósito desse estudo, sequencialmente serão apresentados os pressupostos teóricos que embasam a pesquisa, pautados em especialistas nos principais 
temas abordados, como Libâneo (2013) ao mencionamos nosso posicionamento sobre ensino; Moran (2012); Bacich (2018) e Diesel, Baldez e Martins (2017) que contribuíram para o que concebemos como Metodologias Ativas e Métodos Ativos no ensino.

Também foram importantes para o desenvolvimento do estudo Krasilchik (20II) que nos forneceu informações sobre como as disciplinas de Práticas de Ensino/Didáticas estão sendo apresentadas aos acadêmicos de licenciatura em Biologia, e Berbel (20II) que fundamenta nosso entendimento sobre A.B.P. entre outros autores que com seus estudos e teorias fundamentaram esta pesquisa. Por conseguinte, iniciaremos com o Ensino, relatando como ele é entendido nesse estudo.

\subsection{Ensino}

Entende-se que as finalidades educacionais comportam as concepções de homem e sociedade de cada momento histórico e contexto socioeconômico que o ser humano vivencia. Dessa forma, objetivos, conteúdos e métodos caracterizam o modo de pensar e agir, o que reflete os interesses de cada grupo social. A Pedagogia é, portanto, subordinada à uma concepção político social (LIBÂNEO, 2013). Por tal entendimento, a educação escolar é "uma atividade social que, por intermédio de instituições próprias, visa a assimilação dos conhecimentos e experiências humanas acumuladas no decorrer da história, tendo em vista a formação dos indivíduos enquanto seres sociais” (Ibid, p. 53).

Nessa etapa da discussão, convém observar o que acontece com as disciplinas de Ciências e Biologia ao longo da Educação Básica. Marandino, Selles e Ferreira (2009) mencionam que os conteúdos da disciplina de Ciências possuem um caráter mais geral, sendo ministrada no período reservado ao Ensino Fundamental, ao passo que Biologia, no Ensino Médio, tem uma aproximação maior com o campo das Ciências Biológicas. São, portanto, disciplinas distintas, porém tratam de "conhecimentos escolares em Biologia vinculados às demandas socioculturais dos alunos das diversas faixas etárias” (Ibid, p. 23). É possível relacionar o exemplo dessas disciplinas com o conceito de educação escolar, que é concebida como uma ação não neutra, carregada de concepções e ideologias acerca do mundo, da sociedade e da cultura. Marandino, Selles e Ferreira (2009, p. 23) 
mencionam que "na escola existem transformações de conhecimentos mais diretamente relacionados às finalidades de ensino”. Portanto, as informações prestadas na educação escolar são definidas a partir de conhecimentos e valores envolvidos na sociedade, que são históricos e sociais, bem como, que integram os sujeitos nos universos profissional, social e cultural (CARVALHO, 2015).

É nesse processo de educação escolar que a Pedagogia intervém, orientando os objetivos a serem alcançados, criando condições, a partir de metodologias que viabilizam a apropriação e assimilação das informações científicas existentes por partes das novas gerações humanas. Nesse sentido, a didática entra em campo, para assegurar que a ação pedagógica aconteça na escola, na sua dimensão político-social e técnica, através de seu objeto de estudo: o ensino. Este, por sua vez, comporta os conteúdos escolares, metodologias, técnicas e estratégias. O ensino é a ferramenta utilizada pelo docente para assegurar que as novas gerações aprendam as informações construídas durante a história humana.

A partir do entendimento sobre o ensino é importante saber que nem sempre ele acontece dentro dos ambientes formais, as vezes podemos ensinar e aprender em outras locais, pois também é compreendido aqui que aprender é uma ação que acontece no convívio social, conforme Demo (2002) portanto, uma aprendizagem ativa, assim convém esclarecer melhor como chegamos a essa compreensão, apresentando a seguir a Aprendizagem Ativa.Z

\subsection{Aprendizagem Ativa e Método Ativo}

As muitas conversas, atividades e informações que fazem parte da vida de qualquer indivíduo, são experiências que conduzem a aprendizagens, ajudam a entender o mundo e o auxiliam lidar com os desafios da sociedade. Entretanto, durante o processo de crescimento e amadurecimento, tais momentos podem não se constituir em aprendizagens simples, e sim complexas. Isso porque, muitas vezes, são exigidas das pessoas competências de que elas ainda não dispõem, mas que, ao enfrentá-las no cotidiano, acabam por adquiri-las forçosamente (BACICH; MORAN 20I8). 
Nesse sentido, entende-se que, quando a pessoa vivencia, pensa, reflete e toma as decisões cabíveis, posiciona-se diante das situações, e é protagonista de sua vida, ela está desenvolvendo competências de forma ativa. Isso converge com Moran (BACICH; MORAN, 2018, p. 2) segundo o qual "a vida é um processo de aprendizagem ativa, de enfrentamento de desafios cada vez mais complexos". Assim a aprendizagem durante a vida é complexa.

É importante conduzir o processo de aprendizagem como evolução teórica e prática no que se refere à necessidade permanente de relacionamento com o contexto social, utilizando estratégias didáticas e metodológicas que instiguem o questionamento reconstrutivo (DEMO, 2002). Para tanto, há a necessidade de proporcionar atividades lúdicas, ou atividades que estimulem o hábito da leitura e o manejo eletrônico, visto que podem influenciar positivamente no desenvolvimento do pensamento crítico (Ibid, 2002).

Tal perspectiva converge com o ensino de Ciências/Biologia, foco deste trabalho. É preciso trabalhar com essa disciplina a partir do que temos em sala de aula, na escola e na comunidade na qual a escola está situada. Após faz-se a escolha de um método científico, em que constam os conceitos teóricos, as ideias, as interpretações, as experiências que, muitas vezes, vão de encontro ao senso comum. Sendo assim, justifica-se que a disciplina de Ciências precisa ser vista em seu aspecto social.

Assim, a sala de aula precisa ser compreendida como um espaço de criação de conhecimentos, construído pelo professor a partir de questionamentos. Dessa forma, o aluno é instigado a refletir sobre o que sabe, pois a natureza e a vida cotidiana são fontes inesgotáveis de perguntas e de grandes experimentos (GOLOMBEK, 2009).

Em vista disso, reafirma-se que a melhor maneira para contribuir com o ensino das disciplinas está na integração das metodologias ativas ao planejamento e execução das aulas. Conforme Bacich e Moran (2018, p. 27) a "aprendizagem ativa constitui alternativas pedagógicas que colocam o foco do processo de ensino e de aprendizagem no aprendiz, envolvendo-o na aprendizagem por descoberta, investigação ou resolução de problemas”.

Diesel, Baldez e Martins (2017, p. 270-27I) complementam esse posicionamento, referindo que uma abordagem voltada para o método ativo é, "uma possibilidade de 
deslocamento da perspectiva do docente (ensino) para o estudante (aprendizagem) [...]. No método ativo, os alunos ocupam o centro das ações educativas e o conhecimento é construído de forma colaborativa".

Por esse entendimento, a proposta curricular da ABP, também conhecida pelo termo em inglês Problem Based Learning (PBL) encontra-se inserida no conjunto das metodologias ativas e favorece a aprendizagem por meio do diálogo, da análise e da pesquisa sobre a realidade (BERBEL, 20II). Na próxima seção, essa metodologia será aprofundada.

\subsection{Aprendizagem Baseada em Problemas}

No Brasil, a proposta de ABP esteve primeiramente integrada nos currículos de medicina. Porém, há alguns anos, vem ingressando em outros cursos, uma vez que se diferencia das demais metodologias até então adotadas, por favorecer o aprendizado técnico-científico numa proposta curricular (BERBEL, 20II).

Salienta-se que a integração da ABP nas aulas contribui para, conforme Freitas (20II, p.04) “criar hábitos de estudo e de pensamento pelo método da experiência reflexiva" possibilitando a construção de autonomia na aprendizagem, com ênfase na aprendizagem ativa, pois favorece a tomada de iniciativa e de decisões. Trata-se de uma possibilidade de "superar a tão criticada separação entre a formação acadêmica e a realidade concreta, entre teoria e prática" (Ibid, p. os).

E considerando as afirmações de Pimenta e Almeida (20II), sobre o ensino nos cursos de Licenciaturas, no qual salientam que geralmente nas ações educativas nesse ambiente, predominam as metodologias voltadas para a transmissão de conteúdo pelo professor, ao passo que o aluno desempenha uma atitude passiva e receptiva, entende-se que a inserção de métodos ativos como a $\mathrm{ABP}$ constitui um avanço para os processos de ensino e de aprendizagem. Nesse sentido, acredita-se que, especialmente no espaço universitário, a metodologia de ABP seja fundamental, pois "professor cria condições para o aluno perceber-se perplexo mediante determinada questão ou situação problema e questionar-se" (FREITAS, 20II, p. 04). 
A A.B.P inspirou-se, conforme Berbel (1998, p. 148) nos ideais da Escola Ativa, do Método Científico, a partir de um ensino "Integrado e Integrador dos conteúdos, dos ciclos de estudo e das diferentes áreas envolvidas, em que os alunos aprendem a aprender e se preparam para resolver problemas relativos à sua futura profissão". Dessa forma os acadêmicos são chamados a participar ativamente do processo de ensino e aprendizagem, possibilitando experienciar situações práticas da sua futura profissão, o que contribui para a formação de pessoas melhor preparadas.

Em outras palavras, é preciso pensar a formação inicial do professor, sobretudo daquele que atuará no ensino básico, intencionando garantir um ensino que permita aos alunos aprenderem a construir atividades inovadoras, as quais levem-nos a evoluir, tanto em relação aos conceitos quanto em relação a suas aplicações. Dessa forma, criam-se condições para que consigam, durante o exercício profissional, orientar seus futuros aprendizes a alcançarem os objetivos propostos da disciplina/área em que atuam. Nesse viés, Berbel (20II, p.29) complementa:

Podemos entender que as Metodologias Ativas se baseiam em formas de desenvolver o processo de aprender, utilizando experiências reais ou simuladas, visando às condições de solucionar, com sucesso, desafios advindos das atividades essenciais da prática social, em diferentes contextos.

Cabe referir, ainda, que as metodologias ativas se constituem em uma importante referência para a atuação construtiva do docente, junto a seus alunos. "Ou seja, quanto mais alternativas de atuação pedagógica o professor tiver experimentado/desenvolvido durante a sua formação inicial, melhores condições pessoais e profissionais disporão para atuar com seus alunos" (BERBEL, 20II, p. 36).

Com base nos estudos de Berbel (2011), Martins, Silva e Strohschoen (2015) e Enermark e Kjaersdam (2009), a ABP desenvolve-se a partir dos seguintes passos: os alunos dividem-se em grupos; o professor apresenta situações-problemas aos grupos (pode ser o mesmo problema para todos os grupos, ou cada grupo de receber um problema diferente); a partir dessas situações, os alunos dever realizar pesquisas com base em referencial teórico consistente; a pesquisa será a base para reflexões individuais e debates 
em grupo, buscando uma solução para o problema; por fim, a solução do grupo é apresentada para o grande grupo.

A partir dessas ações que constituem a ABP, pode-se afirmar que essa metodologia permite uma aprendizagem por meio de experiências que ajudam a tomar decisões frente a problemas e desafios com que deparamos nas nossas vivências. Tendo em vista que esse é um dos propósitos intrínsecos a esse estudo, pode-se dizer que é conveniente desenvolver a proposta curricular de $\mathrm{ABP}$ com os acadêmicos do curso de formação inicial de professores de Ciências Biológicas, por meio de uma oficina dentro da disciplina Prática de ensino de Ciências. Tendo em vista que se trata de um tema relevante e que demanda mais estudos que atestem seus efeitos favoráveis na concretização dos objetivos da educação, surge o presente estudo inserido nas aulas da formação inicial de professores, próximo tópico a ser comentado.

\subsection{Formação de inicial de Professores e a Prática de Ensino de Biologia}

Compreende-se que a formação inicial deve dotar o pretenso professor de uma base sólida de conhecimentos no âmbito das informações científicas, culturais, contextuais, psicopedagógicos, práticos e pessoais. Essa base possibilita-lhe agir reflexivamente em seu fazer pedagógico, apoiando sua ação em uma fundamentação válida e significativa para “evitar cair no paradoxo de ensinar a não ensinar" (IMBERNÓN, 20II, p. 63).

Para evitar esse paradoxo, a formação acadêmica deve reforçar "a necessidade de problematizar, o conteúdo das memórias dos alunos e, particularmente, de suas ideias a respeito do ensino de Ciências e Biologia, para melhor entender a influência que tem em seu aprendizado profissional" (MARANDINO, SELLES; FERREIRA, 2009, p. 79). Nesse sentido, é oportuno questionar sobre o que está de fato recebendo atenção no âmbito das disciplinas ofertadas dentro dos cursos de licenciaturas, especialmente das que estão diretamente ligadas à área pedagógica, como a Didática e a Práticas de Ensino.

Como esta pesquisa abordou o ensino de Ciências Biológicas, faz-se necessário conhecer, de forma mais aprofundada, aspectos relativos à sua prática. Portanto, o próximo 
tópico traz consigo nossa visão geral de como está sendo ensinada essa disciplina nas instituições de Ensino Superior.

Ambas as disciplinas, Didática e Práticas de Ensino, estão inclusas nas matrizes curriculares dos cursos de licenciaturas. Nelas, aborda-se que ensinar é uma ação complexa, que exige que o professor não só conheça profundamente a área que leciona, sua história e a importância dos conteúdos inerentes a ela, como também saiba transformar essas informações em uma linguagem que seus alunos aprendam.

Em resumo, é preciso introduzir na formação inicial uma metodologia de ensino que seja presidida pela pesquisa e que vincule constantemente, teoria e prática. Além disso, a formação deve priorizar o desenvolvimento de atitudes críticas, de cooperação e de trabalho em grupo. Deve-se, acima de tudo, preparar os professores para que tornem possível a melhoria da profissão (IMBERNÓN, 20II).

Independentemente da área de estudo (Ciências Exatas, Naturais, Humanas entre outras), cabe à disciplina Prática de Ensino articular três aspectos importantes: "mais do que articular (ligar), precisa interagir com as outras disciplinas pedagógicas, com as disciplinas de conteúdo específicos e com as escolas em que os licenciados realizam os estágios" (BORGES, 200o, p.79).

Em se tratando especificamente da preparação para a atuação na área da Biologia, os acadêmicos necessitam compreender os conceitos básicos de sua área e, para tanto, precisam vivenciar o método científico, analisando as implicações sociais do desenvolvimento da Biologia. Sendo assim, esses futuros profissionais precisam desenvolver a habilidade de escolher os conteúdos mais relevantes, fundamentais e atualizados. "Em seguida devem selecionar as atividades e experiências que melhor levem a consecução dos objetivos” (KRASILCHIK, 20II, p. 79).

Nessa mesma linha, conforme Mendes e Munford (2005), estudos apontam que a disciplina Prática de Ensino no curso de Biologia por vezes está centrada na elaboração de materiais didáticos e em atividades que têm por base questões que a universidade julga relevantes para o ensino de Ciências e Biologia. No entanto, a prática de ensino deve ser 
vista como um espaço de pesquisa, que busca romper a dissociação entre teoria e prática, recorrentemente encontrada nos cursos de formação inicial.

Assim, a concepção adotada neste trabalho é que a disciplina Prática de Ensino de Biologia deve ser voltada para teorias, metodologias, estratégias e técnicas de ensino, que mostrem caminhos de como fazer para promover a contextualização dos conteúdos da área, oportunizando, dessa forma, valiosas experiências profissionais ao acadêmico. Quando a disciplina tem caráter dialógico e parte da realidade, torna-se capaz de induzir a aprendizagem reflexiva e autônoma dos futuros professores.

Sendo assim, reafirma-se que a disciplina Prática de Ensino de Biologia integra prática e conhecimentos teóricos por meio de sua aplicação, reflexão, debate e reelaboração. Além disso, muitas vezes, é nesse componente curricular que o acadêmico tem o primeiro contato com o real e contínuo escolar, como espaço de produção e apropriação de conhecimentos (MENDES; MUNFORD, 2005, p. 208). Assim, caso não houvesse uma disciplina como essa no currículo acadêmico, o futuro professor correria o risco de não refletir acerca de seus conhecimentos sobre ensino, embasando seu ato pedagógico no senso comum.

Para que isso não ocorra, é preciso que, na formação inicial, se considerem as fontes de experiências pré-profissionais, para ressignificar, de forma a fazer com que o futuro docente as valide ou as invalide. Uma maneira de fazer isso é integrar progressivamente essas atividades às aulas da disciplina, por meio de problematizações, por exemplo, dentro das possibilidades formadoras dos cursos de licenciaturas, favorecendo um aprendizado reflexivo com significado (MARANDINO, SELLES; FERREIRA, 2009). Esclarecidos os aportes teóricos que sustentam a abordagem deste estudo, passa-se, a partir de agora, a discorrer sobre os procedimentos metodológicos adotados ao longo do estudo. Trata-se de uma etapa fundamental da pesquisa, que atesta seu rigor científico do estudo.

\section{Procedimentos Metodológicos}

Este capítulo objetiva descrever os caminhos metodológicos que foram empregados para realização desta pesquisa, ou seja, relata as etapas pelas quais a investigação passou. 
Sendo assim, abordar-se-á, dentre outros aspectos, o tipo de pesquisa realizada, suas técnicas e procedimentos, os sujeitos envolvidos e os critérios de avaliação.

Para alcançar o objetivo proposto, foi desenvolvida uma oficina, intitulada: "Metodologias ativas na formação inicial de professores: $O$ ensino de ciências a partir da ABP" no período de 22 de agosto a 26 de setembro de 2019 , ás quintas-feiras, totalizando cinco encontros, no turno da tarde, com carga horária de 20 horas, integrando alguns conteúdos de Ciências da Educação Básica à ABP.

A população alvo foram I6 acadêmicos da turma de 2017 que conforme já referido, essa oficina aconteceu ao longo da Disciplina Prática de Ensino de Biologia I no curso de licenciatura em Ciências Biológicas da Universidade Federal do Oeste do Pará, Campus Rondon, em Santarém - PA. Este estudo segue uma abordagem qualitativa, aproximandose, em alguns aspectos, da pesquisa-ação. Utilizou - se como instrumentos para coleta de dados: diário de itinerância, fotos, gravações em vídeos, questionários avaliativos e subjetivos com perguntas abertas.

Os sujeitos envolvidos assinaram um Termo de Consentimento Livre e Esclarecido (TCLE) em que manifestaram ciência dos passos deste estudo e concordaram em participar. Durante a oficina os 16 acadêmicos foram denominados de $\mathrm{P}_{1}, \mathrm{P}_{2}, \mathrm{P}_{3}$ consecutivamente até o Pı6. A oficina integrou, durante sua execução, alguns conteúdos de Ciências da Educação Básica à proposta metodológica ABP.

O estudo foi concretizado na Universidade Federal do Oeste do Pará (UFOPA), localizada no município de Santarém, interior do Estado do Pará, Campus Rondon. Foi a primeira Instituição Federal de Ensino Superior com sede num ponto estratégico da Amazônia, no município de Santarém, terceira maior cidade paraense, mundialmente conhecida por suas belezas naturais, com destaque para o encontro das águas dos rios Tapajós e Amazonas (UFOPA, 20II).

\subsection{A oficina}

Nos encontros a pesquisadora informou aos acadêmicos que a oficina abordaria a proposta de $\mathrm{ABP}$ e, para tanto, pediu que os participantes formassem quatro grupos. Como 
na turma havia 16 acadêmicos, seriam 4 grupos compostos por 4 membros. Ao avançarmos nas atividades da oficina, entregou-se a cada grupo uma reportagem que abordavam os seguintes temas: Gravidez na Adolescência; Movimentos Antivacinas; Aterro Sanitário de Santarém; Drogas nas Escolas.

Tendo organizado os grupos, os membros deveriam eleger, entre eles, um novo líder e um novo secretário, a cada encontro. Além disso, a cada encontro, deveriam anotar no Diário quem desenvolveria a função naquela semana. Em grupo, os acadêmicos leram as reportagens e tiveram um tempo para dialogarem sobre as informações constantes na notícia e em seguida, receberam uma situação-problema referente à notícia recebida pelo grupo, anteriormente, a qual deveria ser lida com atenção, todos os encontros seguiram os passos da ABP.

\subsection{Análise dos dados coletados}

A fim de melhor compreender os resultados do estudo, as informações coletadas foram organizadas dentro de quatro categorias. Como parâmetro para a escolha das categorias, foram utilizados os objetivos específicos dessa pesquisa. Segue a relação das categorias:

I. Análise sobre o que os licenciados sabem acerca das metodologias ativas e do método da Aprendizagem Baseada em Problemas.

2. Perspectivas docentes sobre utilizar o método Aprendizagem Baseada em Problemas para ensinar Ciências Naturais ou Biológicas na Educação Básica.

3. Principais dificuldades apontadas pelos alunos para desenvolver Aprendizagem Baseada em Problemas em suas aulas.

4. Evidências do aprendizado pós oficina.

A organização das categorias está relacionada aos objetivos, geral e específicos, para melhor compreender os resultados. Os acadêmicos foram instigados a partir de perguntas com a intenção de estimulá-los a pensar sobre o que vinham pesquisando, fazendo as anotações em seus diários de itinerância. 
A organização e análise dos resultados da pesquisa em categorias favoreceu visualizar a proposta metodológica de $\mathrm{ABP}$ em prática e suas contribuições para o ensino de Ciências, haja vista que impulsionou os acadêmicos a reverem seus conceitos sobre didática, muitas vezes enraizados no senso comum. Além disso, a maioria dos participantes julgaram ser viável utilizar a $\mathrm{ABP}$ na Educação Básica, favorecendo o aprender a aprender de forma crítica e autônoma.

Das respostas obtidas, depreende-se que os participantes já conheciam alguns aspectos inerentes à ABP. Isso ficou evidenciado, de forma clara, na resposta do participante $\mathrm{P}_{\mathrm{I}}$ - O professor-facilitador traz uma situação problema e os alunos trabalham na solução dos problemas, quando afirmou que o professor é um facilitador, responsável por apresentar uma situação-problema aos alunos.

O participante $\mathrm{P}_{12}$ complementou, afirmando - O professor apresenta um enunciado com uma problemática de um contexto social, por exemplo, e os alunos irão analisar, os motivos daquele problema e encontrar uma solução. A partir da visualização prática da problemática apresentada dentro de um contexto social conhecido. Segundo esse pesquisado, cabe aos alunos analisar os motivos daquele problema e encontrar uma solução. Essas ideias convergem com as considerações apresentadas na seção do aporte teórico deste estudo, quando se mencionou que, nessa metodologia, a aprendizagem se dá por meio de experiências que ajudam a tomar decisões frente a problemas e desafios (BERBEL, 2008).

$\mathrm{Na}$ categoria 2 com base nas respostas dos participantes de I a 9 infere-se que, em sua atuação profissional, já como professores, o método ativo estudado seria aplicado, visto que, de acordo com as respostas, há evidências de que a proposta metodológica de ABP favoreceria, na percepção deles, o ensino de Ciências e Biologia. Como pode-se evidenciar, dos 16 participantes, Io responderam à questão, destes, 9 responderam que aplicariam a proposta em suas aulas. Um participante afirmou que não aplicaria, pois ele se considera "meio tradicional". O participante argumentou que, considerando a série e o aluno, a metodologia poderia não funcionar. 
Com essa exposição do pensamento manifestado na resposta do participante $\mathrm{P}_{9}$, retomam-se as palavras de Moran (2012), que, ao falar dos principais obstáculos a uma educação inovadora, cita justamente a cultura da aula tradicional, que leva os professores a privilegiarem o ensino, a informação e o monopólio da fala. Nessa perspectiva, o autor ainda menciona que, aliado isso, está o excessivo número de alunos, turmas, aulas e matérias que alguns professores acabam acumulando, lhe restando pouco ou nenhum tempo para planejar aulas.

Para as dificuldades apresentadas, conforme a categoria 3 , é possível verificar nas respostas dos acadêmicos, que os investigados demonstram preocupação advinda do tempo de duração da metodologia, visto que a escola básica não tem esse tempo disponível. Tal preocupação é pertinente, contudo, conforme já referido, ensinar e aprender exigem, nos dias de hoje, que os conteúdos engessados deem espaço a um ambiente educacional no qual os processos de ensino sejam mais abertos à comunicação e à pesquisa (MORAN, 2012).

Nesse contexto, o papel do educador é "mobilizar o desejo de aprender, para que o aluno se sinta sempre com vontade de conhecer mais" (MORAN, 2012, p. 33). Sendo assim, a preocupação dos investigados ainda está muito atrelada ao conteúdo engessado, abordagem essa que é refutada por estudiosos da educação contemporânea, como é o caso do Moran (2012).

Tomado desse ângulo, a aprendizagem depende cada vez mais do aluno e, para que ela aconteça de forma a atender as demandas educacionais, é preciso um novo olhar sobre o como ensinar. Nessa perspectiva, convém a introdução de metodologias ativas no ensino, visto que focalizam a postura autônoma do aluno. É o caso da $\mathrm{ABP}$, proposta que tira o foco do conteúdo que o professor quer ensinar, favorecendo os debates, a pesquisa e a açãoreflexão-ação (Ibid, 2012).

O fato de vivenciar experiências diferenciadas e, a partir disso, pensar sobre suas ideias, transgredindo-as, tem relevância dentro da categoria 4, pois as respostas dos participantes nos fizeram refletir acerca dos indícios de que houve aprendizado pós oficina, haja vista, em seus relatos mencionarem uma reflexão sobre as práticas pedagógicas até então conhecidas ou adotadas por eles. As respostas que seguiram essa característica se 
enquadrarem na possibilidade de posturas diferenciadas, a partir da reflexão sobre a prática e uma possível mudança de comportamento didática, quando partirem para sua atividade profissional, já que conforme Freire (1996).

A partir dos relatos, constatou-se que cada participante fez referência a pelo menos um momento específico da oficina que mais se interessou em participar, pois o considerou como estímulo de sua aprendizagem como afirmou a $\mathrm{P}_{3}$ - Me senti mais à vontade na aplicação dos temas abordados pelas equipes. Nas rodas de conversas e colocação de questões, onde foi possível todos apresentarem seus pontos de vista, abrindo um espaço para debate, e ao mesmo tempo havendo uma troca de conhecimentos entre os acadêmicos. Nesses momentos, os participantes vivenciaram situações não usuais em sua vida acadêmica, pois puderam expressar-se livremente durante as aulas e vivenciar um método ativo. Essas referências mostram indícios de que houve estímulos a uma aprendizagem formal mais ativa.

Os participantes $\mathrm{P}_{9}$, Pio, Pi3, por exemplo, citaram que o momento com o qual mais se identificaram foi a dinâmica final. Como justificativa, apontam a importância da culminância do estudo feito pelos colegas, que possibilitou interação entre os grupos realizada nessa aula. Essa perspectiva é ratificada pela resposta do participante P9: "me identifiquei frente aos assuntos mostrados pelos colegas”.

Nesse sentido, os resultados apresentados pelos grupos fizeram com que os participantes vissem a concretização da aprendizagem e, por intermédio dessa visualização prática, passaram a considerar a $\mathrm{ABP}$ um caminho que leva ao conhecimento. Conforme Moran (2012, p. 43), o gosto "vem do desejo de conhecer e da facilidade em fazê-lo. A facilidade depende do domínio técnico da leitura, da escrita, da capacidade de análise, comparação, síntese, organização de ideias de aplicação”.

Entretanto, os participantes $\mathrm{P}_{1}, \mathrm{P}_{2}, \mathrm{P}_{3}$ e $\mathrm{P}_{4}$ indicaram um interesse maior pelo processo de aplicação, ao citar os momentos de pesquisa, planejamento e discussões em grupo. Possivelmente, essas foram as ocasiões em que se comprometeram com as atividades, tendo a oportunidade de entender melhor não só os temas em estudo, mas 
também a dinâmica de aplicação prática da ABP. Esses investigados indicaram como pontos positivos a troca de informações e a discussão.

Baseado nesse comprometimento dos participantes, pondera-se que adquiriram uma visão mais ampla do processo de ensino. A partir dessa oficina, os participantes assimilaram que, de fato, explicar seja mais do que expor. Ademais, são necessários recursos diversos para aproximar o aluno da compreensão do objeto de estudo (BACICH; MORAN, 2018).

Nesse sentido, os resultados apresentados pelos grupos fizeram com que os participantes vissem a concretização da aprendizagem e, por intermédio dessa visualização prática, passaram a considerar a $\mathrm{ABP}$ um caminho que leva ao conhecimento. Conforme Moran (2012, p. 43), o gosto "vem do desejo de conhecer e da facilidade em fazê-lo. A facilidade depende do domínio técnico da leitura, da escrita, da capacidade de análise, comparação, síntese, organização de ideias de aplicação”.

\section{${ }_{4}$ Considerações Finais}

Conforme visto no decorrer desse trabalho, ensinar é o ofício do professor. Também se evidenciou que ensinar não é fácil, pois envolve uma ruptura de paradigmas tradicionais e alguns até tidos como inovadores. A sociedade em que vivemos está em constante mudança e, assim, os docentes ensinam na incerteza do que os alunos realmente precisam saber para construir uma vida profissional digna e de sucesso. Nesse mesmo viés, o conhecimento científico está em constante mudanças, devido as novas descobertas feitas num intervalo de tempo cada vez menor.

Dessa forma, ensinar anseia por tornar a aprendizagem mais ativa, convergindo com uma abordagem de ensino focada nas metodologias ativas, que são meios promissores para se atingir a aprendizagem. Pensando por esse prisma, evidenciou-se, na proposta metodológica de Aprendizagem Baseada em Problemas, que o método ativo é capaz de instigar os alunos a se comprometerem com sua aprendizagem.

As etapas dessa metodologia envolvem problemas contextualizados, diálogos e construções em grupos de trabalho, visando desvendar ou solucionar um problema identificado pelo professor. Para chegar às soluções, os alunos valem-se de seus 
conhecimentos prévios, de pesquisas, de debates e de organização das ideias em prol da melhor solução. Nesse sentido, os alunos constroem relações de confiança com os colegas, aprendem a dialogar e a entrarem em acordo sobre os próximos passos do trabalho.

A aplicação da oficina trouxe algumas informações nesse sentido. Ao finalizá-la, por meio da avaliação, foi possível perceber que a ABP favoreceu uma vivência acadêmica pré-profissional, que através das respostas dos acadêmicos e da participação destes nas atividades e questionamentos propostos durante a oficina, foi possível perceber indícios de que houve uma mudança reflexiva na forma como os participantes viam o processo de ensino.

É importante ressaltar que, na sua aplicabilidade, houve momentos de dificuldades e tensão, tanto no que concerne ao entendimento da proposta, quanto em relação ao envolvimento dos participantes. Isso se deve, possivelmente, por se estar lidando com pessoas diferentes, com trajetórias de vida também diferentes, que já traziam consigo uma imagem do que é ser professor e de como ensinar, oriundas de suas experiências enquanto alunos, também da educação básica.

A realização da oficina também revelou aspectos importantes sobre a metodologia de ABP. Evidenciou-se que é uma proposta viável de ser aplicada no curso de formação inicial de professores, uma vez que, por meio dessa vivência, os futuros professores viram-na em prática e consideraram-na um método capaz de facilitar o processo de ensino de Ciências e Biologia na Educação Básica.

Assim, percebeu-se que $A B P$ se tornou um método eficaz para o ensino, principalmente no que tange a ensinar alguns conteúdos do Ensino Básico, já que foi possível contextualizá-los, trazendo problemas da sociedade para discussões e pesquisas. Com isso, as aulas foram transformadas em um ambiente em constante produção.

A culminância da oficina foi a apresentação desses resultados, em forma de aula, para os colegas. Este foi um momento bastante comentado pelos alunos, inclusive em suas avaliações, em que deixaram claro que a maioria dos participantes compreendeu o conceito e sua aplicabilidade, indicando ser uma estratégia que consideram adequada às aulas de Biologia ou Ciências, quando se tornarem professores. Isso significa que, de modo geral, os 
futuros professores acolheram a forma como a ABP lhes foi apresentada, mencionado que aplicarão a referida metodologia nas suas aulas, seja de Ciências ou Biologia.

Com isso, a cada momento da oficina, os participantes revisitaram conceitos sobre didática, muitas vezes ainda enraizados no senso comum. Durante a oficina, refletiram sobre a teoria e a prática de ensino dos conteúdos, enquanto resolviam as situaçõesproblemas. Durante a avaliação, reconheceram a ABP como proposta metodológica de ensino viável de ser aplicada e capaz de favorecer o aprender a aprender de forma crítica e autônoma, com base em sua recente experiência com a proposta.

Assim, considera-se que a forma como a proposta metodológica de ABP foi aplicada nas aulas de formação inicial de professores de Ciências Biológicas, durante a disciplina de Prática de ensino de Biologia I, promoveu estímulos ao aprendizado, no que concerne a uma mudança na forma de pensar dos participantes a respeito da relação da didática com os conhecimentos científicos.

Diante desse entendimento, ratifica-se que integrar a Aprendizagem Baseada em Problemas às aulas, na formação inicial, colabora para que os futuros professores reflitam sobre a dinamicidade do ensino e sobre a importância de rever práticas atreladas ao senso comum, enraizadas em suas experiências pré-profissionais, questionando-as. Com base nisso, novas percepções sobre seu ofício na escola básica são criadas, visando estabelecer um ensino com base na pesquisa autônoma e no diálogo.

\section{REFERENNCIAS}

BACICH, Lilian; MORAN, José (Orgs). Metodologias Ativas para uma educação inovadora: uma abordagem teórico-prática. Porto Alegre: Penso, 2018.

BERBEL, Neusi Aparecida Navas. A Problematização e a aprendizagem baseada em problemas: diferentes termos ou diferentes caminhos. Interface (Botucatu), v. 2, n. 2, p.139154, 1998. Disponível em: 〈http://www.scielo.br/pdf/icse/v2n2/o8.pdf > Acesso: 22 mar. 2019.

BORGES, Gilberto Luiz de Azevedo. Formação de Professores de Biologia, Material Didático e Conhecimento Escolar. Tese Doutorado. Faculdade de Educação, São Paulo: Universidade Estadual de Campinas, 200o. Disponível em: <http://www.educadores. diaadia.pr.gov.br/arquivos/File/2010/artigos_teses/Biologia/Teses/formacao.pdf > Acesso em: or mai. 2020 . 
CARVAlHO (Org.). Ensino de Ciências: unindo a pesquisa e prática. São Paulo: Cengage Learning, 2015.

DEMO, Pedro. Educar pela pesquisa. Campinas. Autores associados, 2002.

DIESEL, Aline; BALDEZ, Alda; MARTINS, Silvana. Os princípios das metodologias ativas de ensino: uma abordagem teórica. Revista Thema, v. I4, p. 268-288, 2017. Disponível em: < http://revistathema.ifsul.edu.br/index.php/thema/article/view/404 > Acesso em: 20 jan. 2018.

FREITAS, Raquel Aparecida Marra da Madeira. Ensino por problemas: uma abordagem para desenvolvimento do aluno. Goiás, 20II. <http://www.scielo.br/pdf/ep/2oinahead/aop478.pdf > Acesso: 22 mar. 2019.

GOLOMBEK, Diego A. Aprender e ensinar Ciências: do laboratório a sala de aula (viceversa) [tradução Eloisa Cerdan] 2.ed. São Paulo, Sangari Brasil. Fundação Santillana, 2009.

IMBERNÓN. Formação docente e profissional: Formar-se para mudança e a incerteza. Trad. LEITE, Silvana Cobucci. $9^{\underline{a}}$ ed. v.I4. São Paulo: Cortez, 201 .

JÓFILI, Zélia. Piaget, Vygotsky, Freire e construção do conhecimento na escola ${ }^{\mathrm{x}}$. Educação teorias e práticas, ano 2, no 2, Universidade Católica de Pernambuco.

Disponível em: 〈https://www.maxwell.vrac.puc-rio.br/7560/756o.PDF> Acesso em: 20 maio 2019.

KRASILCHIK, Myriam. Prática de Ensino de Biologia. $3^{\underline{a}}$ reimpr. São Paulo: $4^{\underline{a}}$ ed. Ver e ampl. Universidade de São Paulo. 2orı.

LIBÂNEO. Didática. São Paulo, 2 ed. Cortez, 2013

MARANDINO, Marta. SELLES; Sandra Escovedo; FERREIRA, Márcia Serra. Ensino de Biologia: Histórias e práticas em diferentes espaços educativos. São Paulo, Cortez, 2009.

MENDES, Regina; MUNFORD. Danusa. Dialogando com os Saberes - Pesquisa e Prática de ensino na formação de professores de Ciências e Biologia. Revista ensaio. Belo Horizonte, v. 7, 2005. Disponível em: <http://www.scielo.br/pdf/epec/v7n3/1983-2117epec-7-03-00202.pdf> 
MORAN, José Manuel. A educação que desejamos: Novos desafios e como chegar lá. $5^{\text {a }}$ ed. São Paulo: Papirus, 2012.

PIMENTA, Selma Garrido; LIMA, Maria do Socorro Lucena. Estágio e Docência. Rev. Ténica, FUSARI, José Cerhi. Coleção Docência em Formação: saberes Pedagógicos, 6. ed. São Paulo: Cortes 2010.

POZO, Juan Ignacio; CRESPO, Miguel Ángel Gómes. A Aprendizagem e o Ensino de Ciências: do conhecimento cotidiano ao científico. Trad. Naila Freitas, $5^{\underline{a}}$ ed. Porto Alegre: Artmed, 2009. 